\title{
The formation of primary school teachers' professional readiness for teaching Russian as a foreign language using the opportunities of cross-border education
}

\author{
Svetlana Belovitskaya ${ }^{1, *}$, Tatyana Guseva ${ }^{2}$, Irina Shatokhina ${ }^{2}$, Elena Shcherbina ${ }^{2}$ \\ ${ }^{1}$ Don State Technical University, Russia \\ ${ }^{2}$ Southern Federal University, Russia
}

\begin{abstract}
The article is devoted to the problem of using the opportunities of cross-border education as a factor of professional training of primary school teachers for tuition Russian as a second language. The authors note the relevance of this problem both in theoretical aspects and at the practical level. The article describes an effective way to form the readiness of primary school teachers to implement cross-border education. In this study, the authors reveal new opportunities for professional development of primary school teachers.Based on the content analysis of the regulatory database, it is shown that this problem is related to an upward trend in the Russian higher education system. The article reveals the relationship between teachers' professional training in the field of tuition Russian language to younger students, for whom Russian is a second language, and the existing problems with using Online learning. The article substantiates the need for training primary school teachers, which contributes to the development of their professional competencies both in the Offline mode of training and the Online training. A set of pedagogical measures related to the professional training of primary school teachers to teach Russian as a non-native language in cross-border education can become one of the foundations for the development of the Russian Federation education system. The article is addressed to the teachers of higher and secondary vocational training institutions, as well as future and certified teachers of primary General education.
\end{abstract}

\section{Introduction}

In our days the formation of professional readiness of primary school teachers is undergoing qualitative changes, which subsequently generalize, systematize and open up new pedagogical opportunities for both teachers and students. Due to the dynamism of social and political changes in the world, teacher training is one of the most important factors in improving the competitiveness of the education system. Investigating the competitiveness of modern teachers, in particular primary school teachers, it is important to emphasize their ability to compete in the global educational market, i.e. the ability of primary school teachers

\footnotetext{
* Corresponding author: belovickaja-svetlana@rambler.ru
} 
to provide better and more affordable education in comparison with colleagues from other educational organizations, regions, and countries.

It should be noted that in the "State Program of the Education Development in Russian Federation ", approved by RF Government Decree 2017/12/26 № 1642 (ed. 2020/08/11), the main purpose of Russian education is the quality of education characterized by: ensuring global competitiveness of education in Russia, entering Russia into 10 countries leading in the quality of General Education [1]. The high degree of competitiveness of the education system ensures the harmonious development of Russian society at the international level.

In their research, E. Shcherbina and P. Pivnenko note that "in the system of continuing education, the role of primary school as its foundation and the institution of socialization of the nation is increasing..." [2]. It is worth noting that the current global social situation requires the education system to create such pedagogical conditions where every student, regardless of their location and residence, would have the opportunity to study the educational program of an educational institution.

At present, a certain characteristic of the professional readiness of primary school teachers to use the opportunities of cross-border education is the purposeful educational process of organizing the activities of a future teacher to master professional competencies and develop their skills to apply the acquired competencies in everyday teaching activities, taking into account modern requirements. This idea is illustrated in figure 1 . The figure shows that the components of the educational process that we have taken as the basis of the professional training of primary school teachers for a second language tuition are coordinated. It should be mentioned that the professional training of primary school teachers with the opportunities of cross-border education, in particular Online training, is a process that includes all the components of the educational process in the mode of Offline training.

The use of the figure 1 components of the model of the on-line training of future primary school teachers is considered to be one of the factors that can ensure that the teachers solve the following tasks:

- independent implementation of teaching Russian language to younger students, for whom the target language is a second one;

- professional ability of a teacher to study the methodical features of teaching Russian as a second language;

- the desire of primary school teachers to analyze the need of society for teaching Russian and identify epy existing professional deficits.

We consider this direction as providing educational services aimed at training future primary school teachers to teach Russian as a second language. We consider it relevant the problem of vocational training with the opportunities of cross-border education, in particular Online training. 


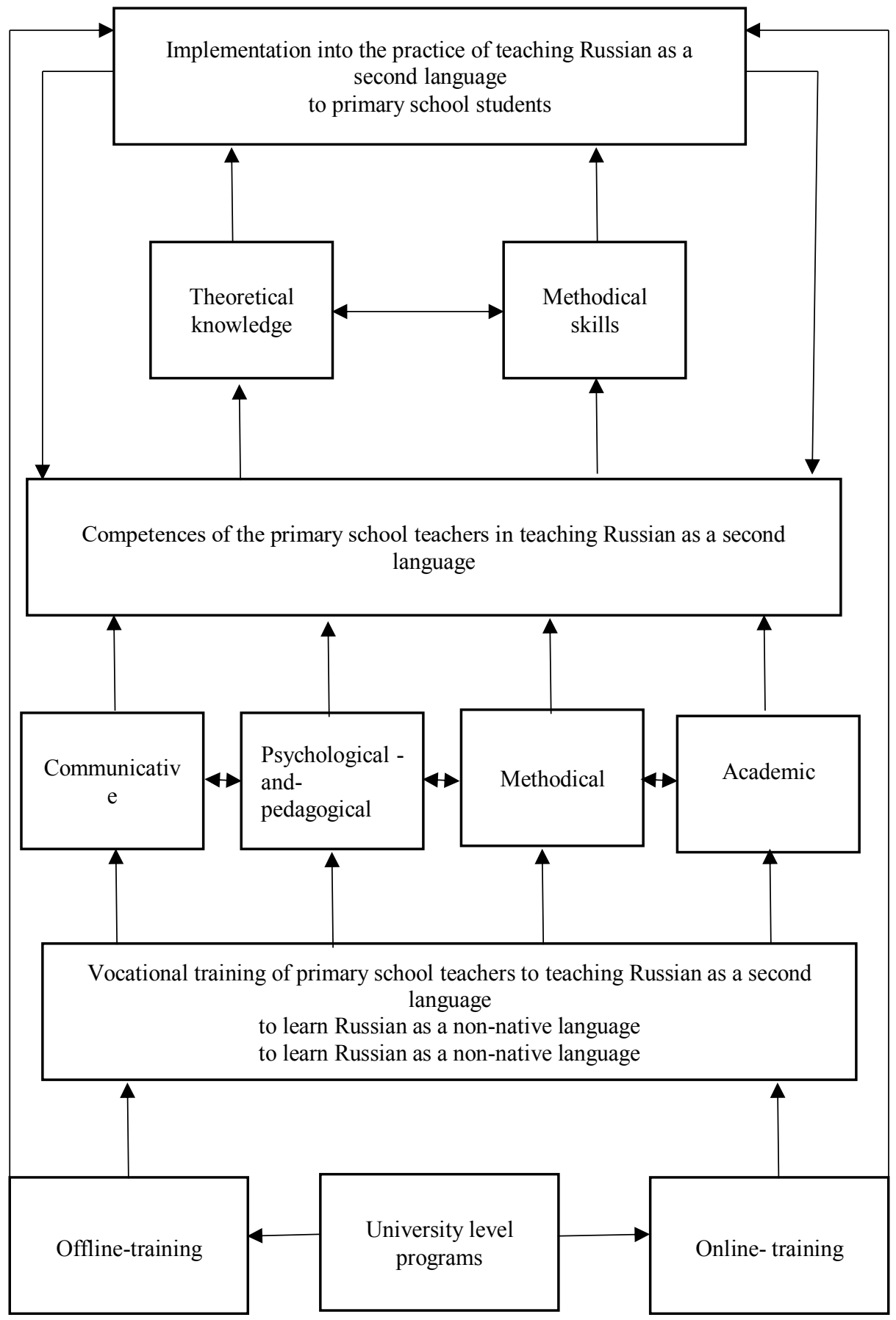

Fig. 1. Components of the model of the training of future primary school teachers to teaching Russian as a second language.

The purpose of the article is to analyze the effectiveness of using the opportunities of cross-border education in the professional training of primary school teachers to teach Russian as a second language. The problem of the research is to establish a link between the 
professional training of a future primary school specialist to teach Russian as a second language and the strategic guidelines for the development of the educational system at the Federal and international levels. Consequently, we formulate the following hypothesis: it is possible that the intensity of the cross-border education development causes the effectiveness of the vocational training of primary school teachers to teaching Russian as a second language.

\section{The concept and methodology of the research}

The empirical array includes the texts of passports and regulatory documents of the Federal level: the Federal Law "On the Education in the Russian Federation", 2012/12/29 No 273FL, adopted by the State Duma on December 21, 2012 and approved by the Federation Council on December 26, 2012, (edited on June 31, 2020) and (with changes and additions entered into force on September 1, 2020); Labor Code of the Russian Federation, 2001/12/30 No 197-FL, adopted by the State Duma on December 21, 2001 and approved by the Federation Council on December 26, 2001 (with changes and additions entered into force on August 13, 2020).; Decree of the RF Government, 2019/08/14 No 1797-R (ed. 2020/06/20) "On the approval of the strategy of services export development by 2025" (with the "Plan of the realization of the strategy of services export development by $2025 »$ ); Order of the Russian Ministry of Education, 2019/05/16 No P-60 "On the approval of the departmental target program "Scientific-and-methodical, methodical and staffing support of teaching Russian language and the languages of the peoples of the Russian Federation" (together with the "Passport of the departmental target program "Scientific-and-methodical, methodical and staffing support of teaching Russian language and the languages of the peoples of the Russian Federation»); Order of the Ministry of Education of Russia, 2017/08/23 No 816 "On the approval of the procedure for the application of organizations engaged in educational activities, E-learning, distance educational technologies in implementation of educational programs" (Registered in Ministry of Justice of Russia 2017/09/18 No 48226).

Research methods: cluster analysis, content analysis, generalization, comparative analysis, interpretation.

\section{Results and debate}

At the first stage of the study, we set the task of determining the goals of the official documents and the system of measures for the development of education in the Russian Federation. In our opinion, an important aspect of the development of the educational system, according to paragraph 12 of Article 2 of the Federal Law " On the Education in the Russian Federation" is: vocational education - the type of education that is aimed at acquiring knowledge, skills by students and the formation of their competencies of a certain level and volume that allow them to conduct professional activities in a certain field and (or) perform specific professions or specialties [3].

The qualification of a primary school teacher is assessed by the level of professional competencies that characterize teacher's readiness for educational activities.

Analyzing the Federal State Educational Standard of Higher Education - bachelor's degree in the field of training 44.03.01 "Pedagogical Education" (Registered in the Ministry of Justice of the Russian Federation 2018/03/15 No 50362), approved by the Order of the Ministry of Education and Science of the Russian Federation on February 22, 2018 No 121., we concluded that, a future specialist is learning to solve pedagogical, project, methodical, organizational and managerial, cultural and educational tasks of educational activity [4]. However, the requirements for the results of the bachelor's degree program are not 
sufficiently related to the types of professional activity of primary school teachers that contribute to the implementation of teaching Russian as a second language.

The Analysis of the Passport of the Labor Code of the Russian Federation 2001/12/30 No 197-FL, adopted by the State Duma on December 21, 2001 and approved by the Federation Council on December 26, 2001 (with changes and additions entered into force on August 13, 2020) has shown that the Russian Federation provides equal opportunities for employees without any discrimination in career advancement, taking into account labor productivity, qualifications and work experience, as well as training and further professional education (ed. Federal law No. 185-FL 2013/07/02) [5]. Thus, we can conclude that effective teaching primary school children to Russian as a second language is an indicator of the productivity of educational activity of primary school teachers. Consequently, increasing the productivity of educational activity, the specialist increases the level of professional competencies.

Studying the requirements for learning outcomes on the bachelor's degree program presented in the Federal State Educational Standard of Higher Education, we came to the conclusion that the formation of 15 categories of general-professional and universal competencies of the graduates correspond to the formation of the professional readiness of primary school teachers for teaching. However, only two of general-professional and universal competencies (UC) can be associated with the teacher's ability to teach Russian as a second language using the tools of cross-border education.

For example, the ability of a certified primary school teacher to determine the set of tasks and choose the best ways to solve them, basing on current legal norms, available resources and restrictions (universal competence (UC)-2) [4] reflects the teacher's readiness to teach primary school children Russian as a second language. Such professional competence as the ability to carry out business communication in oral and written forms in the state language of the Russian Federation and foreign language(s) (UC-4), [4] is associated with the professional training of a future teacher using cross-border education. The results of the analysis are shown in figure 2.

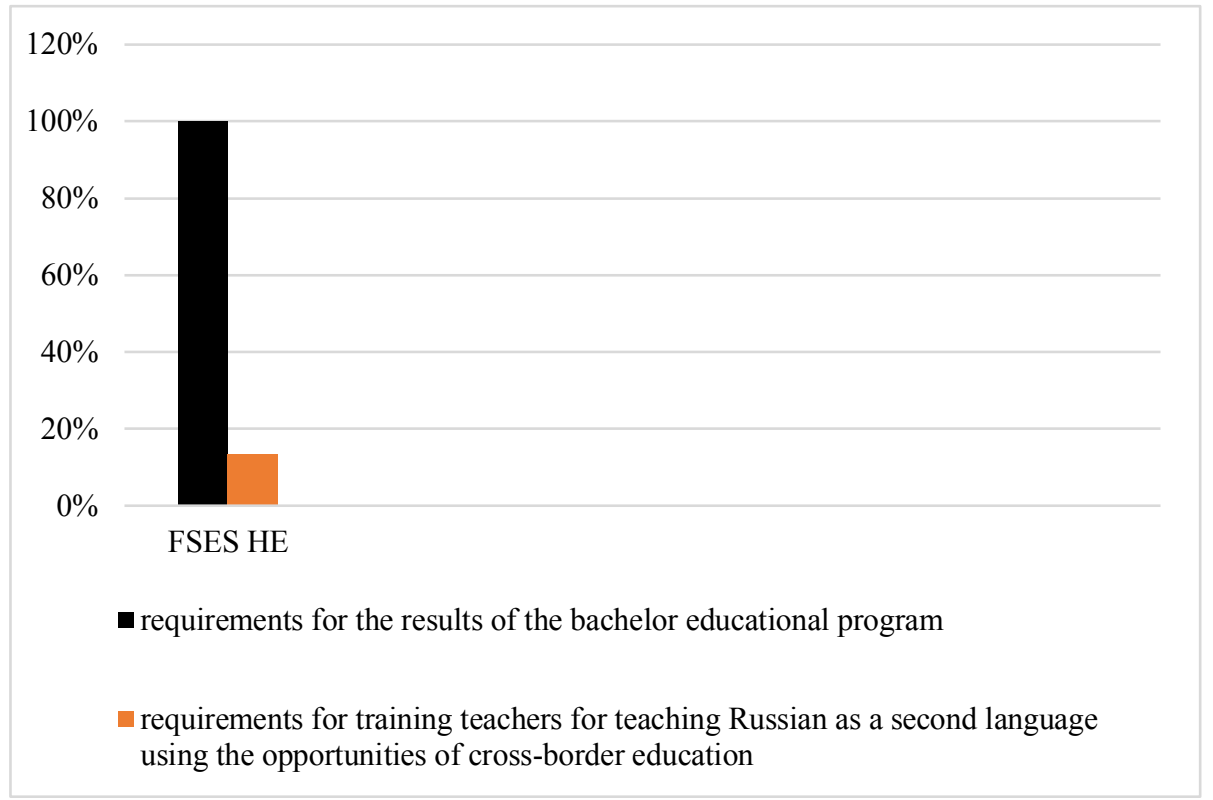

Fig. 2. Percentage of the requirements for the results of bachelor's degree programs that contribute to teachers training for teaching Russian as a second language using the opportunities of cross-border education. 
The histogram shows that among the number of requirements for the results of bachelor's degree programs $(100 \%)$, an insufficient number of requirements correlates with the formation of readiness of primary school teachers to teach Russian as a second language using the opportunities of cross-border education (13.33\%).

The second stage of the analytical study was related to the definition of goals and a system of pedagogical measures to implement the opportunities of cross-border education in the formation of the readiness of primary school teachers to teach primary school children Russian as a second language. The necessity of forming professional competence of primary school teachers was substantiated.

In the pedagogical works of I. V. Shatokhina, the problems concerning modern primary education are revealed. One of these problems is that "... primary school teachers pay insufficient attention to the purposeful formation of younger students' educational activities " [6]. As a result, primary school teachers were not sufficiently prepared to organize the educational activities of younger students. The labor activity of a teacher who organizes the educational process at the initial stage is understood as the provision of educational services to students in all subjects studied

It should be noted that the training of primary school teachers is multidimensional. In addition to professional competencies in the form of methodical, psychological, pedagogical and communicative skills, the future primary school teacher needs to develop subject skills. Features of professional readiness of primary school teachers are as follows: the knowledge of all the subjects taught at the first stage of education, as well as the ability to apply the knowledge in practice. Thus, a primary school teacher is an agent of multi-subject pedagogical activity, he introduces the younger student to a great number of educational areas. Thus, it's particularly relevant for primary school teachers to be ready to teach Russian to junior children who live in the different regions of the world and study Russian as a second language.

In the Decree of the RF Government from 14.08.2019 No 1797 -R (edited on 2020/06/20) "On the approval of the strategy of services export development by 2025" (along with the "Plan of the realization of the strategy of services export development by 2025") the main segments of the international market of the educational services are revealed, they include:

- all types of international mobility of students, learning foreign languages, in the fields of higher, secondary and primary education;

- transnational training (cross-border education) (as the provision of educational services in the country other than the home country of the educational institution);

- related educational products and services (assignment of internationally recognized qualifications; services in the field of educational technologies, and others) [7]. Consequently, the training of primary school teachers as an aspect of the national education system is a public request for the training of highly qualified teaching staff.

The analysis of pedagogical research by T. K. Guseva and N. K. Mayatskaya shows that the concept of "a teacher" is close to the concepts of "clergy", "army", "students", "Cossacks", in which the main feature is belonging to a certain type of professional activity, in this case pedagogical activity [8]. It should be emphasized that the above-mentioned concepts are similar in meaning not only as a professional component, but also as a social one.

And as mentioned earlier, the professional training of primary school teachers is multidimensional and socially oriented. We consider, one of the purposeful factors of training primary school teachers is the formation of a future teacher's methodical skills to strengthen positions of the Russian language and to teach in Russian, while using cross-border education. The popularization of Russian language and culture at different international levels is stated in the departmental target program " Scientific-and-methodical, methodical and staffing support of teaching Russian language and the languages of the peoples of the Russian Federation " ((together with the "Passport of the departmental target program 
"Scientific-and-methodical, methodical and staffing support of teaching Russian language and the languages of the peoples of the Russian Federation»); approved by the Order of the Russian Ministry of Education, 2019/05/16 No R-60 [9].

The development of digital technologies and the globalization of communications powerfully stimulate e-learning markets [7]. Russian education technologies have almost unlimited potential [10]. When used effectively, they can be a means of obtaining education, a tool for organizing the educational process and managing it, an information resource for teaching Russian and in Russian, and a source of forming the professional competence of primary school teachers. According to S. I. Belovitskaya, O. E. Sirotkin, R. M. Chumicheva "this approach should be considered in the context of technologization of the innovation process - ensuring its diagnostics, manageability, consistency, efficiency and effectiveness" $[11,12]$.

\section{Conclusion}

Based on the above, as well as the analysis of the scientific works of K. E. Dyachkova, D. S. Zueva, G. V. Semenov, S. A. Timofeev, O. D. Fedotova, K. S. Fursova, A. B. Ertel, we note that the rapidly developing technological process is being quickly implemented in the practice of education. And, accordingly, higher education programs include different types of training. The use of network educational projects in order to form the professionalism of teachers is discussed in the scientific works of G. V. Semenov, S. A. Timofeev, O. D. Fedotova, A. B. Ertel. They reveal the effective use of these educational tools in training competitive teaching staff [13-15].

Thus, we have determined that comprehensive diversification of Russian education, in particular primary education, turns into the support of the professional training of primary school teachers for teaching Russian as a second language with the possibilities of Online learning. We revealed the opportunities of the cross-border education in training qualified professionals who are able to use the above mentioned tools and ready to teach Russian to younger students for whom Russian is a second language, both in the educational institutions of our country, and outside the Russian Federation.

\section{References}

1. Decree of the Russian Federation Government 2017/12/26 No 1642 (ed. 2020/08/11) "On approval of the Russian Federation the state program "Development of education"

2. E.N. Shcherbina, P.P. Pivnenko, Pedagogical science and education in Russia and abroad: regional, global and informational aspects 1, 37-42 (2006)

3. Federal law" On education in the Russian Federation "2012/12/29 No 273-FZ, adopted by the State Duma on December 21, 2012 and approved by the Federation Council on December 26, 2012, (edited on June 31, 2020) and (with changes and additions entered into force on September 1, 2020)

4. Federal State Educational Standard of higher education-bachelor's degree in the field of training 44.03.01 "Pedagogical education" (Registered in the Ministry of justice of the Russian Federation 2018/03/15 No 50362), approved by the order of the Ministry of education and science of the Russian Federation on February 22, 2018 No 121

5. Labor Code of the Russian Federation 2001/12/30 No 197-FL, adopted by the State Duma on December 21, 2001 and approved by the Federation Council on December 26, 2001 (with changes and additions entered into force on August 13, 2020)

6. I.V. Shatokhina, XV regional scientific and practical conference. Implementation of the 
fses of primary general education in modern conditions: innovative practices, problems, prospects (Akadem Lit Publishing House, 2017)

7. Decree of the RF Government 2019/08/14 No 1797-R (edition 2020/06/20) "On approval of Strategy of service exports development by 2025" (with the "Plan of measures on realization of Strategy of development of service exports by 2025»)

8. T.K. Guseva, N.K. Mayatskaya, Proceedings of the Southern Federal University. Pedagogical science 8, 32-38 (2012)

9. Order of the Russian Ministry of Education 2019/05/16 No P-60 "On approval of the departmental target program "Scientific-and-methodic, methodical and staffing support of teaching Russian language and the languages of the peoples of the Russian Federation" (together with the "Passport of the Departmental Target Program "Scientific and methodic, methodic and staffing support of teaching Russian language and the languages of the peoples of the Russian Federation»)

10. K.A. Dyachkova, D.S. Zueva, K.S. Fursov, Cross-border education: current realities and prospects. Scientific works, 92-106 (2008)

11. S.I. Belovitskaya, Pedagogical journal 5A(6), 268-275 (2016)

12. O.E. Sirotkin, R.M. Chumicheva, The world of academia: Culture, Education 9, 81-89 (2018)

13. O.D. Fedotova, A.B. Ertel, Collection of scientific papers of the scientific and practical conference with international participation "socio-cultural problems of education development in the conditions of project management (2018)

14. G.V. Semenov, S.A. Timofeev, O.D. Fedotova, World of science. Pedagogy and psychology 1(8), (2020) https://mir-nauki.com/PDF/62PDMN120.pdf

15. O. Fedotova, E. Platonova, E. Tregubenko, G. Avanesyan, SHS Web of Conferences The conference proceedings, 02004 (State Technical University, 2019)

16. P.V. Petri, V.B. Tripolsky, Law and Education 1, 59 - 67 (2013)

17. N. Negroponte, Being Digital (Knopf, New York, 1995) https://bok.org/book/1188274/ca2aa4, last accessed 2020/09/05

18. Y.-F. Xu, L.-S. Shi, 2020 IEEE 2nd International Conference on Computer Science and Educational Informatization (CSEI), Computer Science and Educational Informatization (CSEI) (2020) DOI 10.1109/CSEI50228.2020.9142491 